\title{
Large-Scale Upwelling off Northwestern Mexico ${ }^{1}$
}

\author{
GunNar I. Roden \\ Dept. of Oceanography, University of Washington, Seatlle 98195 \\ (Manuscript received 20 September 1971, in revised form 8 November 1971)
}

\begin{abstract}
The seasonal variation of large-scale upwelling off northwestern Mexico is investigated by means of the divergence of the Ekman transport, computed for a $1^{\circ}$ latitude-longitude grid. It is found, by using such a close grid, that the vertical velocity is resolved in sufficient detail to bring out many important features of upwelling that agree favorably with the temperature distribution. The limitations of the method are discussed.
\end{abstract}

\section{Introduction}

One of the outstanding features of the eastern North Pacific is the relatively cold water off the California and Baja California coasts. The southward bend of isotherms upon approaching the North American continent and the occurrence of pronounced cold water pockets in low latitudes have been attributed to upwelling for a long time (McEwen, 1912; Sverdrup and Fleming, 1941). The early authors tried to explain upwelling in terms of the local wind stress, that is, the offshore Ekman transport. A qualitative agreement was found to exist between the longshore winds and the coastal sea surface temperatures in some cases (Reid et $a l ., 1958$ ).

A more realistic model of upwelling was developed by Yoshida and Mao (1957). These authors used the vorticity and continuity equations to establish a relationship between the vertical velocity on the one hand, and the wind stress field at the sea surface and the meridional component of geostrophic mass transport on the other. The usefulness of this model has suffered from the inability to resolve the wind stress field in sufficient detail. Upwelling, when judged by its effects upon temperature, occurs in a narrow band of the order of a few hundred kilometers (Yoshida, 1967; Smith, 1968); hence, a closely space grid is needed to bring out even the main features of the vertical velocity distribution.

In this paper, the vertical velocity computations are based on a $1^{\circ}$ latitude-longitude grid, using Yoshida and Mao's (1957) theory. It will be shown that the resolution is sufficient to bring out the principal features of large-scale upwelling and its seasonal variation, and that the findings are in good agreement with the temperature distribution.

${ }^{1}$ Contribution No. 617 from the Department of Oceanography, University of Washington.

\section{Theoretical aspects of upwelling}

It is of interest to discuss briefly the computation of the vertical velocity from the vorticity and pressure equations and to establish a relation between the vertical velocity and temperature fields, because upwelling is often inferred from the temperature distribution.

\section{a. Vertical velocity from the vorticity equation}

The method of Yoshida and Mao is based on the Navier-Stokes equation with lateral friction omitted, and assumes stationary conditions and a linearized velocity field. The horizontal component of the earth's rotation vector is neglected and the equations of continuity and motion are integrated with respect to depth. Applying the vorticity operation to the integrated equation of motion, taking the vertical component of the resulting expression, neglecting the surface slopes, and assuming that the stress vanishes some depth $h$ below the sea surface, such as at the top of the pycnocline, these authors obtain

$$
(\rho w)_{-h}=\left(\nabla \times \frac{p}{f}\right)_{z, 8}-\frac{\beta}{f} \int_{-h}^{s} \rho v_{0} d z
$$

where $\rho$ is density, $w$ the vertical velocity, positive upward at depth $z=-h, f$ the Coriolis parameter, $\beta$ its derivative with respect to latitude, $v_{g}$ the northward component of geostrophic flow, and $\tau$ the wind stress vector at the sea surface $s$.

Eq. (1) shows that the vertical velocity can be obtained from a knowledge of the wind stress field at the sea surface and the density field. The first term on the right represents the divergence of the Ekman transport and has been used to estimate vertical velocities in the North Pacific ocean on a $5^{\circ}$ latitude-longitude grid (Wickett and Thomson, 1969). Such a wide grid with a mesh size of about $540 \mathrm{~km}$ is inadequate to resolve 
features with scales of the order of $200 \mathrm{~km}$, relevant to upwelling off northwestern Mexico (Yoshida, 1967). The second term in (1) involves the meridional component of the geostrophic mass transport in the upper layer. Upwelling is likely to be pronounced in regions where a cyclonic wind stress distribution coincides with southward geostrophic flow.

\section{b. Vertical velocity from the pressure equation}

The equation of pressure change in the ocean can be written as (Eckart, 1962)

$$
\frac{d p}{d t}=c^{2}\left(\frac{d p}{d t}-\frac{a}{c_{p s}} \nabla \cdot \mathbf{q}\right)
$$

where $p$ is pressure, $t$ time, $c^{2}$ the sound velocity squared, $a$ the coefficient of thermal expansion, $c_{p s}$ is the specific heat at constant pressure and salinity, and $\mathbf{q}$ the heat flux vector $\left(\mathrm{erg} \mathrm{cm}^{-3} \mathrm{sec}^{-1}\right)$ positive upward.

Upon introducing the hydrostatic assumption and the Väisälä frequency $N$, where

$$
N^{2}=-g\left(\frac{1}{\rho} \frac{\partial p}{\partial z}+\frac{g}{c^{2}}\right)
$$

$g$ is the acceleration of gravity, and, assuming a steady state, (2) is transformed into (Roden, 1971)

$$
\rho w=\left(-\nabla \cdot \mathbf{q}-\frac{c_{p s}}{a c^{2}} \mathbf{v}_{H} \cdot \nabla_{H} p+\frac{c_{p s}}{a} \mathbf{v}_{H} \cdot \nabla_{H} \rho\right) /\left(\frac{N^{2} c_{p s}}{a g}\right),
$$

linking the vertical velocity to the heat flux divergence, to the vertical stability, and to flow across isobars and isopycnals.

As in the previous case, we shall consider the vertical velocity at $z=-h$, say at the top of the pycnocline. We shall assume that the flow is geostrophic so that the second term in (4) vanishes. We shall also assume that the heat flux $\mathbf{q}$ at depth $z=-h$ can be expressed in terms of temperature gradients (neglecting the influence of salinity gradients upon the heat flux) so that $q=-\kappa \nabla \theta$ and

$$
(\rho w)_{-h}=\left(\kappa \nabla^{2} \theta+\frac{c_{p s}}{a} \mathbf{v}_{H} \cdot \nabla_{H} \rho\right)_{-h} /\left(\frac{N^{2} c_{p s}}{a g}\right)_{-h},
$$

where $\kappa$ is the diffusion coefficient, assumed constant, and $\theta$ is temperature.

An interesting expression linking the temperature field to the field of motion is obtained by equating (1) and (5), i.e.,

$$
\begin{aligned}
\left(\kappa \nabla^{2} \theta\right)_{-h}=\left(\frac{N^{2} c_{p s}}{a g}\right)_{-h}\left[\left(\nabla \times \frac{\tau}{f}\right)_{z, s}\right. & \left.-\frac{\beta}{f} \int_{-h}^{s} \rho v_{g} d z\right] \\
& -\left(\frac{c_{p s}}{a} \mathbf{v}_{H} \cdot \nabla_{H} \rho\right)_{-h} .
\end{aligned}
$$

The Laplacian of temperature can be used as an indicator of cold and warm water cores, depending upon whether it is positive or negative. As is seen from (5) and (6) regions of coldest temperature do not necessarily coincide with those of maximum upward velocity or maximum divergence of the Ekman transport. A close connection between the cold cores and the divergence of the Ekman transport, for example, can be expected only in those geographic regions where the vertical stability does not vanish and where crossisopycnal flow and meridional geostrophic transport in the upper layer are insignificant. It will be shown below that much of the oceanic area off northwestern Mexico belongs to this category.

\section{Observations off northwestern Mexico and adjacent regions}

\section{a. Seasonal variation of wind stress during 1969-70}

The seasonal and spatial variations of wind stress in the eastern subtropical Pacific are shown in Fig. 1. This figure was derived from the monthly mean sea level atmospheric pressures furnished by the National Weather Service (1969, 1970). The pressures at the original $5^{\circ}$ latitude-longitude grid were refined to a $1^{\circ}$ grid by making use of the Birkhoff and Garabedian bivariate elastic spline interpolation method, which is a modified cubic polynomial surface fit (Birkhoff and Garabedian, 1960). The result of this operation is a smooth atmospheric pressure field from which the stress of the geostrophic wind can be computed. ${ }^{2}$ The $1^{\circ}$ grid was chosen in order to bring out the spatial distribution of wind stress in sufficient detail.

The outstanding feature in Fig. 1 is the pronounced seasonal variation of the wind stress. The calmest period is late fall. In November, the northeast trades and associated northerly winds are weak east of longitude $125 \mathrm{~W}$ and the wind stress is less than $1 \mathrm{dyn} \mathrm{cm}^{-2}$ almost everywhere. Only in a small area to the west of Cabo Corrientes does the stress attain values between 1 and $3 \mathrm{dyn} \mathrm{cm}^{-2}$.

With the coming of winter, winds increase. In February, the northeast trade winds and coastal northwesterlies extend eastward to $108 \mathrm{~W}$ and northward to $30 \mathrm{~N}$. The wind stress encountered in this region varies characteristically between 1 and 3 dyn $\mathrm{cm}^{-2}$. Values $>3 \mathrm{dyn} \mathrm{cm}^{-2}$ are found in some localities, most notably off southern Baja California. As the season progresses, this area of high winds moves farther up the coast. The windy conditions in the south are in marked contrast to the calms farther north.

Spring is the windiest season in the subtropical eastern Pacific. In May, the northeast trade winds and coastal northwesterlies are strong everywhere, except

${ }^{2}$ In computing the stress, the traditional drag coefficient of 0.0026 was used. At sea no reduction of geostrophic wind speed and no cross-isobar flow was assumed. On land, the geostrophic wind speed was multiplied by a factor of 0.70 . 

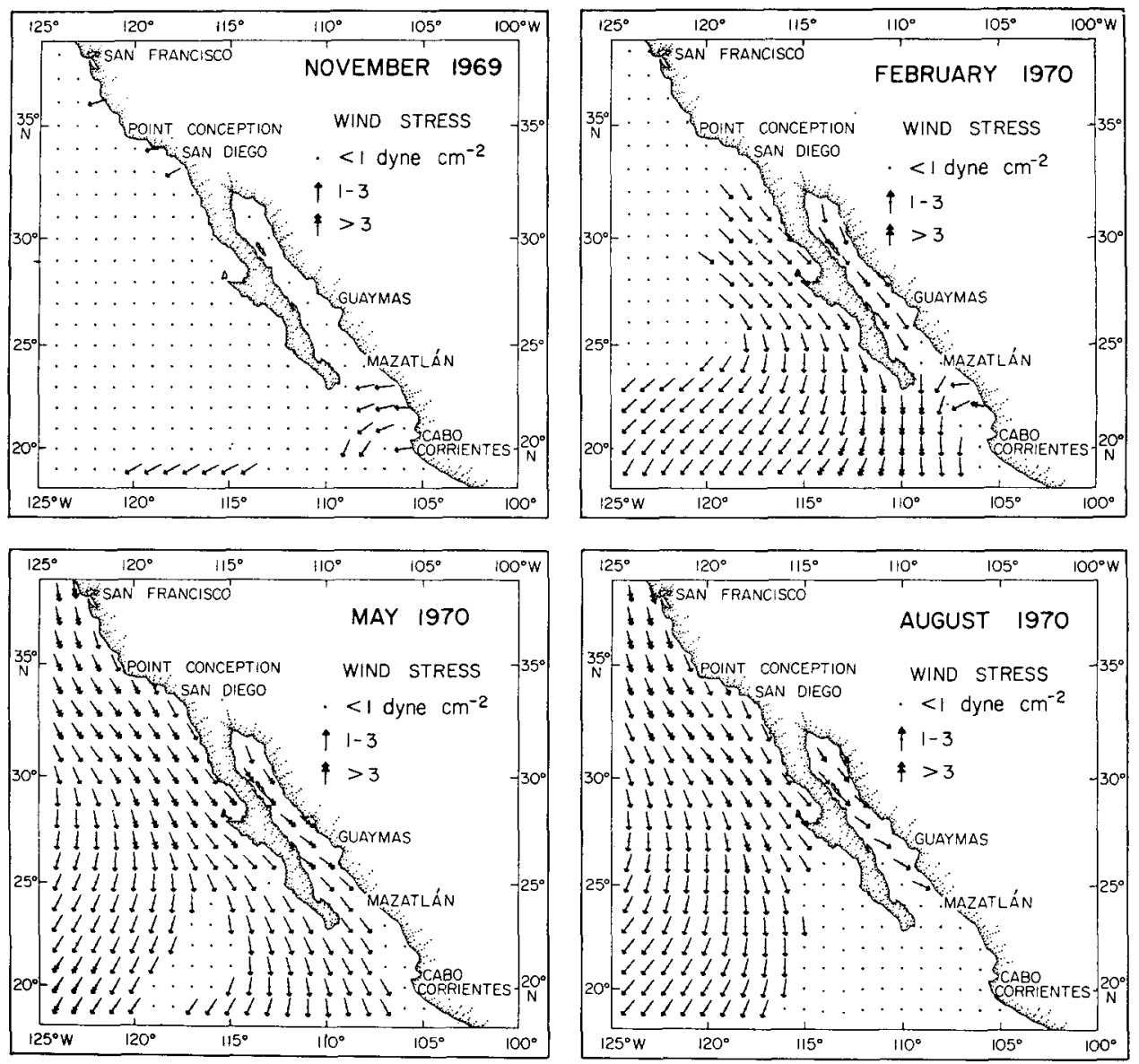

FIG. 1. Seasonal and spatial variation of the stress of the geostrophic wind on a $1^{\circ}$ latitudelongitude grid. Arrows indicate the direction of stress.

for a narrow strip off southern Mexico. There are several areas where the wind stress exceeds 3 dyn $\mathrm{cm}^{-2}$. The most conspicuous of these extends from central California to central Baja California and is about $200 \mathrm{~km}$ wide. In this region, upwelling is prominent and is intimately related to the wind stress distribution, as will be discussed below.

During summer, the winds decrease in magnitude, and the wind maximum in the southern part of the region shifts from the coast offshore. Coastal northwesterlies continue strong off California and northern Baja California, but weaken considerably south of $28 \mathrm{~N}$. During this season, the intertropical convergence zone reaches its northernmost position. The southern part of Baja California and the Revilla Gigedo islands lie in the path of westward-moving tropical disturbances and experience the rainy season. Winds are generally weak and variable, except during the passage of such disturbances, when they sometimes attain hurricane force (De Angelis, 1967).

\section{b. Seasonal variation of Ekman mass transports}

The spatial and seasonal variations of Ekman mass transports are shown in Fig. 2. The outstanding features are the pronounced change in magnitude from fall to spring and the considerable geographical variation at any given time. The spatial variation of Ekman mass transports gives rise to a nonzero divergence field, and hence contributes to upwelling.

In fall, Ekman transports are weak in most of the eastern subtropical Pacific, with the exception of the southeastern part and a narrow belt off the California coast, where northwestward transports $>10^{4} \mathrm{gm} \mathrm{cm}^{-1}$ $\mathrm{sec}^{-1}$ are observed. With the advance of the season, transports increase in magnitude and the direction of transport is generally offshore within a few hundred kilometers of the coast. In winter, transports $>5 \times 10^{4}$ $\mathrm{gm} \mathrm{cm}^{-1} \mathrm{sec}^{-1}$ are encountered south of Baja California, while transports $>10^{4} \mathrm{gm} \mathrm{cm}^{-1} \mathrm{sec}^{-1}$ are observed as far north as $32 \mathrm{~N}$. In spring, transports are strong in almost the entire region, and particularly off northern Baja California, where they exceed $5 \times 10^{4} \mathrm{gm} \mathrm{cm}^{-1}$ $\mathrm{sec}^{-1}$. It is noteworthy that the strongest transports do not occur right at the coast, but some distance offshore. This divergence of the transports strongly favors upwelling, as will be shown below. In summer, Ekman mass transports are weak in the southeastern part of the region, but remain strong elsewhere. There is a 
narrow offshore band of transports in excess of $5 \times 10^{4}$ $\mathrm{gm} \mathrm{cm}^{-1} \mathrm{sec}^{-1}$ extending southward to central Baja California and suggesting upwelling on its eastern side.

\section{c. Seasonal variation of upwelling and its relation to that of temperature}

We shall first assume that the divergence of the Ekman transport alone determines upwelling and then see whether the results obtained compare favorably with the known regions of upwelling as suggested, for example, in the temperature distribution; where this is not the case, the meridional component of geostrophic transport in the upper layer obviously is important.

The seasonal variation of the vertical velocity at the top of the pycnocline is shown in Fig. 3 and is computed from the divergence of the Ekman transport. The seasonal variation of sea surface temperature, which is also indicative of that of the upper mixed layer, is shown in Fig. 4. The map is based on commercial ship observations of sea temperature, averaged for $1^{\circ}$ latitude-longitude squares by the National Marine Fisheries Service $(1969,1970)$. Along the well-traveled shipping lanes, these averages are based on several observations and are quite reliable.
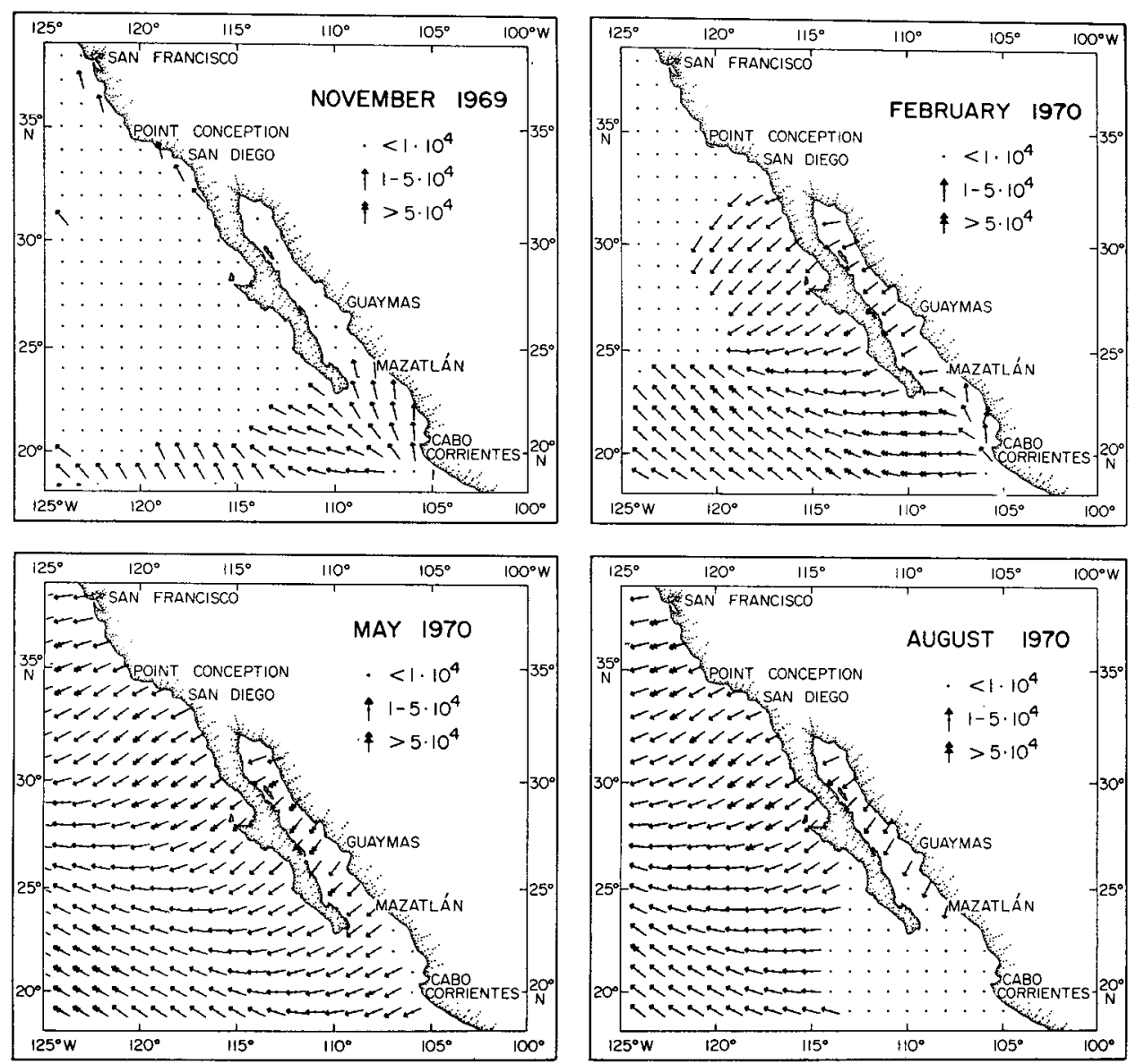

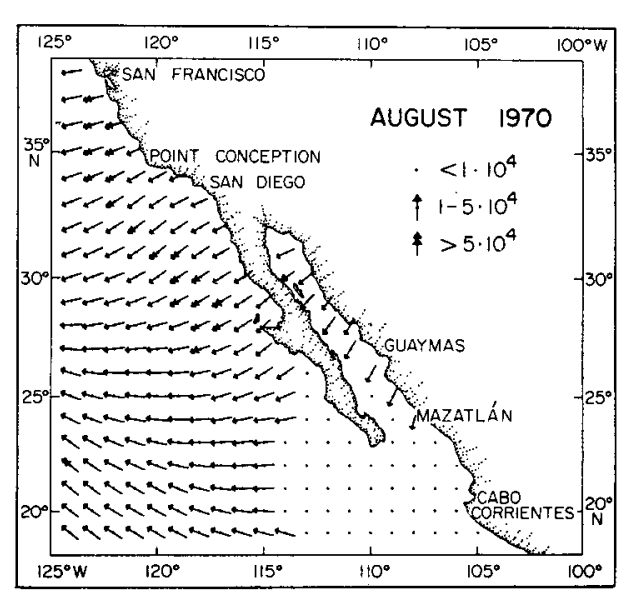

Consider first the west coast of Baja California. In winter, upward speeds $>10^{-3} \mathrm{~cm} \mathrm{sec}^{-1}$ are limited to a small region off northern Baja California. This is also reflected in the temperature map by the $17 \mathrm{C}$ isotherm. In spring, when upwelling is most pronounced, vertical velocities $>10^{-3} \mathrm{~cm} \mathrm{sec}^{-1}$ are encountered in a $150-\mathrm{km}$ band extending from central California to the southern tip of Baja California. In the temperature map, upwelling is suggested by the sharp southward bend of the isotherms west of the peninsula. In summer, strong upward velocities continue to be found from central California to central Baja California, with speeds $>3 \times 10^{-3} \mathrm{~cm} \mathrm{sec}^{-1}$ occurring north of Point Conception. Off southern Baja California, on the other hand, upwelling has almost ceased. Both features are also revealed in the temperature distribution: there is a rather sharp southward bend of isotherms in the region north of Point Conception and a slight northward bend of isotherms off southern Baja California. In late fall, upwelling velocities are small everywhere north of $23 \mathrm{~N}$ and the isotherms tend to be perpendicular rather than parallel to the coast.

The good agreement between the divergence of the Ekman transport and the temperature field off Baja

FIG. 2. Seasonal and spatial variation of the Ekman mass transport on a $1^{\circ}$ latitudelongitude grid. Arrows indicate the direction of transport. 

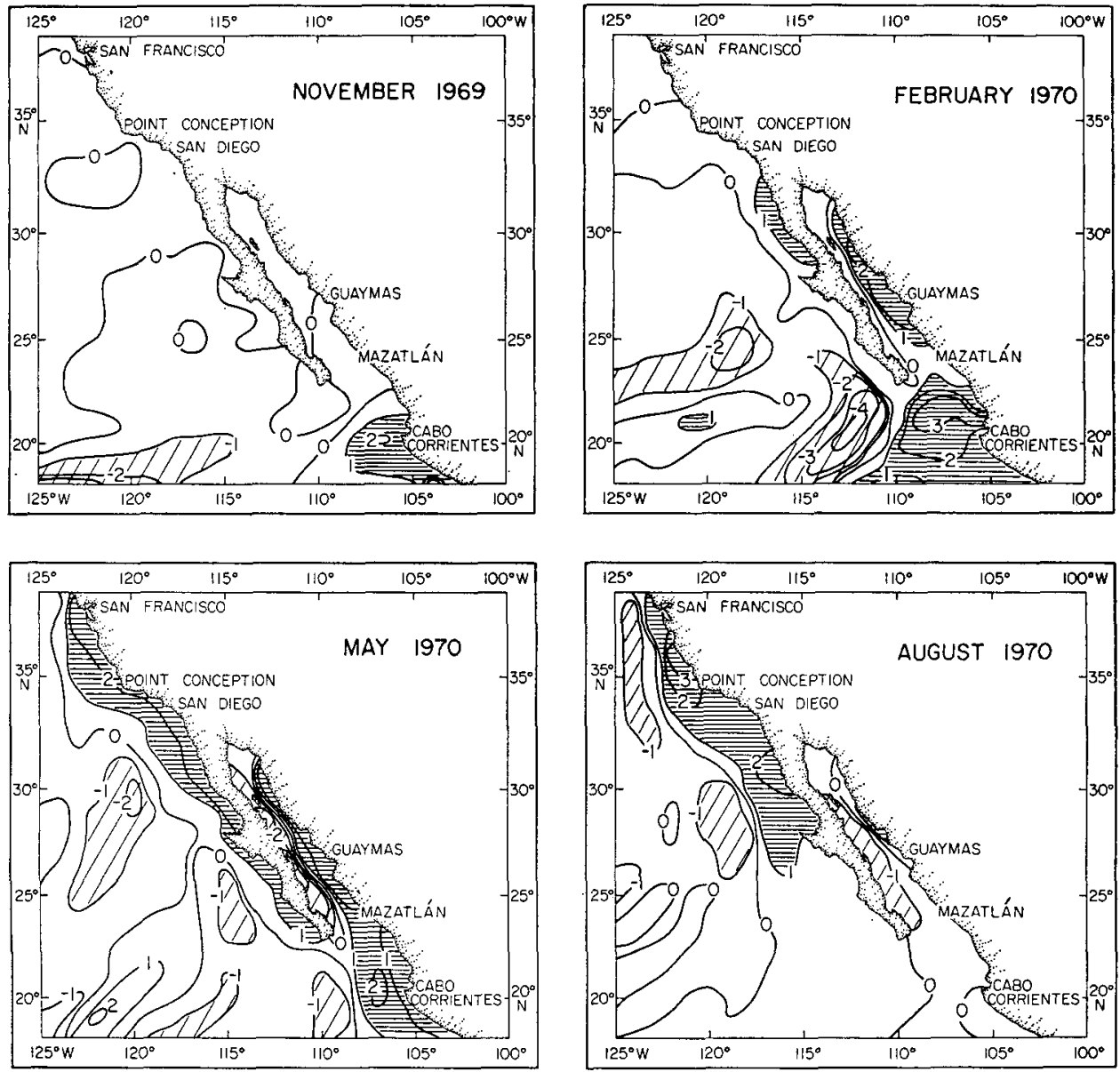

FIG. 3. Seasonal and spatial variation of the vertical velocity resulting from the divergence of the Ekman transport and based on a $1^{\circ}$ latitude-longitude grid. Upward speeds $>10^{-3} \mathrm{~cm}$ $\mathrm{sec}^{-1}$ are indicated by horizontal hatching and downward speeds $>10^{-3} \mathrm{~cm} \mathrm{sec}-1$ by diagonal hatching.

California is indicative that the meridional component of geostrophic transport is small. Typical vertical velocities derived from the divergence of the Ekman transport are $10^{-3} \mathrm{~cm} \mathrm{sec}^{-1}$. If the depth of the upper mixed layer is taken as $50 \mathrm{~m}$ and the average current in this layer is $20 \mathrm{~cm} \mathrm{sec}^{-1}$, which is a high estimate (Scripps Institution of Oceanography, 1963), then the resulting contribution to the vertical velocity from the geostrophic transport is only $10^{-4} \mathrm{~cm} \mathrm{sec}^{-1}$. Thus, over much of the California current region, meaningful estimates of the vertical velocity can be obtained from a knowledge of the wind stress field at the sea surface.

The conclusions derived above are not valid in the vicinity of Cabo Corrientes, to the south of the California current region. Here, the vertical velocity derived from the divergence of the Ekman transport (Fig. 3) suggests strong upwelling from late fall to spring, while the temperature distribution (Fig. 4) indicates the opposite. In view of (6) the disagreement is not too surprising, because the Laplacian of the temperature distribution depends not only upon the divergence of the Ekman mass transport, but also upon the meridional component of geostrophic mass transport in the upper layer, as well as upon cross-isopycnal flow. In the vicinity of Cabo Corrientes, these latter two processes apparently are important.

\section{Conclusions}

Large-scale upwelling off northwestern Mexico is largely determined by the divergence of the Ekman mass transport. In order to bring out the main features of upwelling, such as its concentration in a narrow coastal band, it is necessary to resolve the wind stress field in sufficient detail. By choosing a $1^{\circ}$ latitudelongitude grid, results are obtained that are in pleasing agreement with observations. The method holds promise for other upwelling regions of the earth, where the meridional component of the geostrophic mass transport is weak.

In their original paper, Yoshida and Mao (1957) did not have at their disposal data from which to compute the divergence of the Ekman mass transport; instead, they used geostrophic mass transports in the lower layer from which to estimate the vertical velocity. 

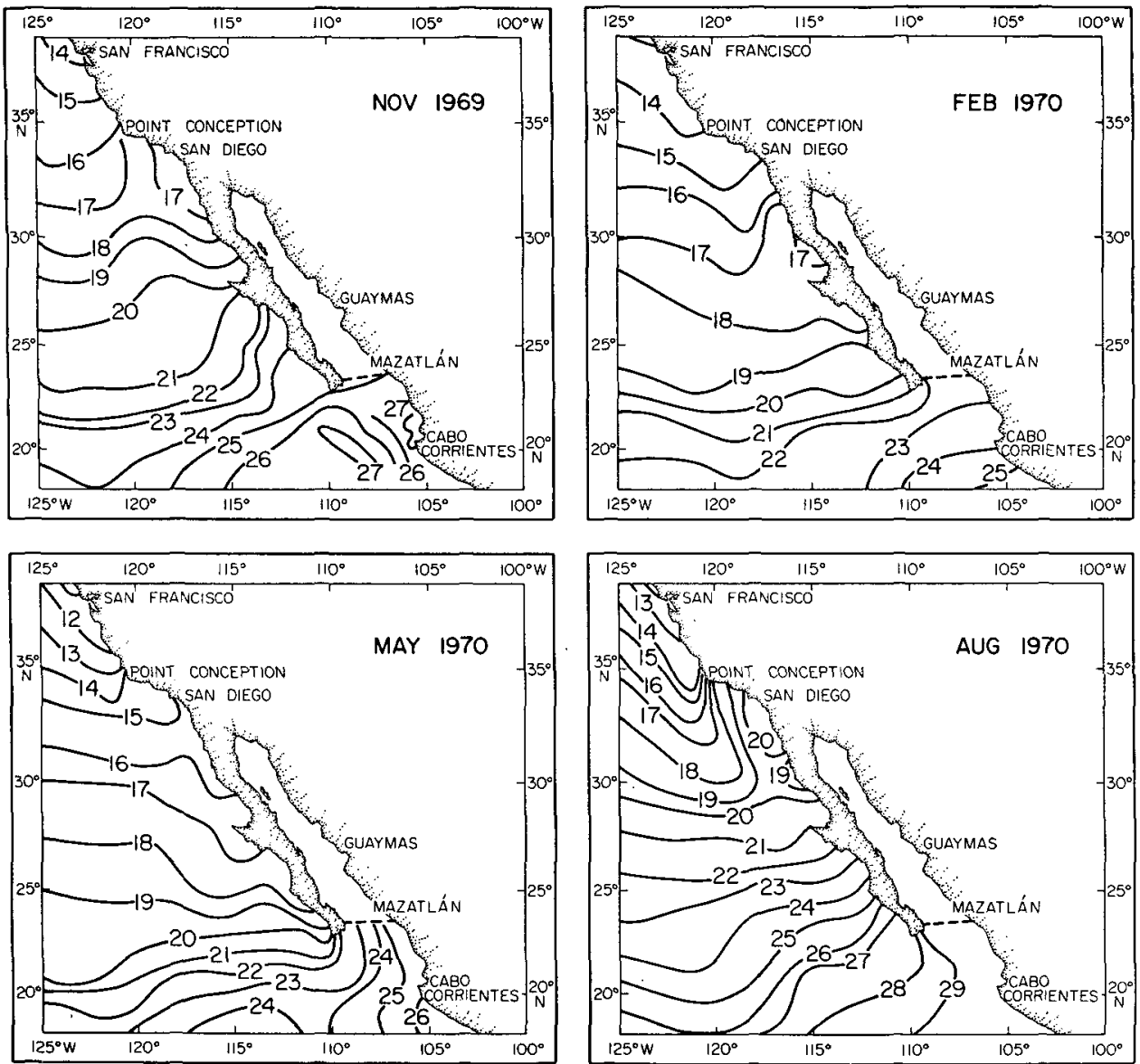

Fig. 4. Seasonal and spatial variation of sea surface temperature $\left({ }^{\circ} \mathrm{C}\right)$ based on $1^{\circ}$ latitudelongitude squares (National Marine Fisheries Service, 1969, 1970).

Their findings were not in good agreement with the known features of upwelling, and the method was little used subsequently. With the availability of hemispheric weather maps and high-speed computers, it is felt that Yoshida and Mao's method (1957) deserves more attention than it has received in the past.

Acknowledgments. I am indebted to M. Rattray for fruitful discussions. C. A. Barnes, R. H. Fleming and L. H. Larsen offered advice, and D. Bendiner carried out the computer programming and calculations. The research reported herein was supported by the Office of Naval Research under Contract N00014-67-A-01030014, project NR 083012.

\section{REFERENCES}

Birkhoff, G., and H. L. Garabedian, 1960: Smooth surface interpolation. J. Math. Phys., 39, 258-268.

De Angelis, R. M., 1967: North Pacific hurricanes. Mariners Wea. Log, 11, 193-200.

Eckart, C., 1962: The equations of motion of sea water. The Sea, Vol. 1, New York, Interscience, 31-41.

McEwen, G. F., 1912: The distribution of ocean temperatures along the west coast of North America deduced from Ekman's theory of upwelling of cold water from adjacent ocean depths. Intern. Rev. Hydrobiol., 5, 243-286.
National Marine Fisheries Service, La Jolla, Calif., 1969, 1970: Fishing Information. (This monthly publication contains sea surface temperatures for the Pacific ocean north of $30 \mathrm{~S}$.)

National Weather Service, 1969, 1970: Monthly mean sea level atmospheric pressure maps for the Northern Hemisphere.

Reid, J. L., G. I. Roden and J. G. Wylie, 1958: Studies of the California current system. Progress Rept., California Cooperative Fisheries Investigation, 1 July 1956-1 January 1958, La Jolla, Calif., 28-56.

Roden, G. I., 1971: Aspects of the transition zone in the northeastern Pacific. I. Geophys. Res., 76, 3462-3475.

Scripps Institution of Oceanography, 1963: CALCOFI Atlas of Geostrophic Flow of the California Current at the Surface and at 200 Meters. University of California, San Diego.

Smith, R. L., 1968: Upwelling. Oceanographic and Marine Biology Annual Review, Vol. 6, London, Allen and Unwin, 11-46.

Sverdrup, H. U., and R. H. Fleming, 1941: The waters off the coast of California, March to July, 1937. Bull. Scripps Inst. Oceanogr., 4, 261-378.

Wickett, W. P., and J. A. Thomson, 1969: Computation of the divergence of Ekman transport for the North Pacific ocean, 1946-1968. Tech. Rept. 128, Fisheries Research Board of Canada, West Vancouver, B. C., 281 pp.

Yoshida, K., 1967: Circulation in the eastern tropical oceans with special reference to undercurrents and upwelling. Japan $J$. Geophys., 4, 1-75.

- , and H. L. Mao, 1957: A theory of upwelling of large horizontal extent. J. Marine Res., 16, 40-57. 